\title{
Evaluation Method for Time-dependent Changes in Combustion Gas of Materials for Railway Rolling Stock
}

\author{
Sho YAMANAKA \\ Tadashi TOYOHARA \\ Mikiya ITO \\ Vibration-Isolating Materials Laboratory, Materials Technology Division
}

\begin{abstract}
Fires occurring on railway rolling stock may not only potentially injure passengers and crew but also damage the rolling stock equipment. It is important to evaluate the performance of materials against fire. Heretofore, the time-dependent production of smoke and toxic gases relating to combustion behavior has not been considered. Quantitative understanding of combustion behavior is important, for example heat release rates, smoke production and gas generation. In the light of this context, the authors designed and fabricated a new combustion test device that can simultaneously measure time-dependent changes of combustion phenomena through combustion tests on materials for railway rolling stock. The combustion performances of materials for railway rolling stock were evaluated based on these results.
\end{abstract}

Key words: railway fire, combustion performance, cone calorie meter fire test

\section{Introduction}

When a fire occurs on railway rolling stock, it is important to immediately evacuate passengers and crew and move the rolling stock to safety on a layby siding, to reduce casualties and damage. In order to improve the fire resistance of rolling stock, it is necessary to decrease the production of smoke and toxic gases that prevent the evacuation of passengers and crew, and to suppress the radiant heat flux to which rolling stock equipment is exposed. Therefore, it is important to evaluate not only the total heat release rate and amount of gas generated from material combustion, but also the time-dependent changes in these amounts. To date however, no adequate evaluation method to meet these needs has defined in European standard, EN45545[1] and International standard. Consequently, the authors originally designed and fabricated a new combustion test device which can simultaneously measure time-dependent changes in certain parameters through combustion tests on materials used on railway rolling stock.

\section{Specifications of the new combustion test device}

In order to evaluate the combustion performance of materials used on railway rolling stock and time-dependent change in gas production simultaneously, the authors investigated a new test device. Table 1 shows the required performance of new test device.

\subsection{Material combustion}

Material combustion methods can be roughly classified into two types: a closed and an open system, depending on the space in which the material is combusted. Limiting the type of combustion test used, to what is commonly applied leads to a set of requirements presented below.

A typical example of a closed system is the smoke density chamber test device used in EN45545 [1], and an example of the latter is the cone calorimeter (CCM) combustion test device.

In the case of combustion tests with closed system, oxygen is not supplied from the outside, and the oxygen inside the space decreases with combustion. In addition, after combustion, the inside of the closed space is contaminated with soot. In order to take accurate measurements, it is necessary to completely remove the soot from the chamber after each test. On the other hand, in the case of CCM with an open system, the heat release rate (HRR) and total amount of heat release (THR) can be measured using the oxygen consumption method, and the smoke production rate is also measured at the same time.

Moreover, only pipes and chimneys are contaminated with soot, which can be easily cleaned. Based on these considerations, the CCM was selected to conduct the new combustion tests.

\section{Table 1 Required performance of new combustion test device}

\begin{tabular}{|c|c|}
\hline Method & Required performance \\
\hline \hline Material combustion & $\begin{array}{c}\text { Measure the HRR and smoke } \\
\text { production rate at same time } \\
\text { Ease of maintenance }\end{array}$ \\
\hline $\begin{array}{c}\text { Evaluation of generated } \\
\text { gas }\end{array}$ & $\begin{array}{c}\text { Short measurement intervals } \\
\text { High sensitivity } \\
\text { Corrosion resistance }\end{array}$ \\
\hline $\begin{array}{c}\text { Introduction of flue } \\
\text { gas into the } \\
\text { measuring device }\end{array}$ & $\begin{array}{c}\text { Uniform collection } \\
\text { Removal of soot from smoke } \\
\text { Corrosion resistance } \\
\text { Ease of maintenance }\end{array}$ \\
\hline
\end{tabular}

\subsection{Evaluation of generated gas}

The gas chromatography (GC method) shown in Fig. 1 and the Fourier transform infrared spectroscopy (FT-IR method) shown in Fig. 2 are commonly used to evaluate gases generated from decomposed materials.

In the case of the GC method, frequent measurement and immediate results are difficult to obtain, as shown in Table 2. In addition, since the column is very thin, soot or other residue can enter the duct, which in turn may become clogged, preventing further measurements.

On the other hand, the FT-IR method enables a qualitative and quantitative evaluation by irradiating a gas passing through a gas cell with infrared. Though the sensitivity is inferior to the GC method, this disadvantage could be adjusted by optimizing the specifications of the gas cell and detector composed the FT-IR as the gas analyzing device of the combustion test device. 


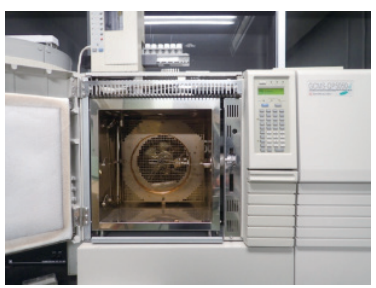

Fig. 1 GC method

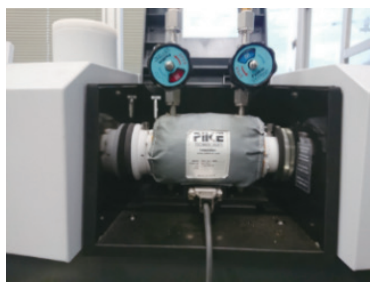

Fig. 2 FT-IR method
Table 2 Characteristics of gas analysis test methods

\begin{tabular}{|c|c|c|}
\hline & \multicolumn{2}{|c|}{ Test methods } \\
\hline Features & GC method & $\begin{array}{c}\text { FT-IR } \\
\text { method }\end{array}$ \\
\hline $\begin{array}{c}\text { Possible to make } \\
\text { frequent measurements }\end{array}$ & $\times$ & $\bigcirc$ \\
\hline $\begin{array}{c}\text { Possible to measure } \\
\text { wide range of } \\
\text { concentrations }\end{array}$ & $\bigcirc$ & $\triangle$ \\
\hline High sensitivity & $\bigcirc$ & $\triangle$ \\
\hline Corrosion resistance & $\triangle$ & $\triangle$ \\
\hline Impurity contamination & $\times$ & $\triangle$ \\
\hline
\end{tabular}

$\bigcirc$ :Suitable, $\triangle$ :Consideration required, $\times:$ Not suitable

\subsection{Introduction of combustion gas method}

The combustion gas is collected from the center of the flue gas duct of the CCM via a vacuum pump using a stainless-steel probe and is introduced to FT-IR as shown in Fig. 3. The tip of the probe is processed at $45^{\circ}$, and it is inserted at an angle of $45^{\circ}$ from the flue gas duct as shown in Fig. 4 to collect combustion gas from the duct to FT-IR. In addition, the applied pipe connecting between the probe and the FT-IR is made of Teflon to improve corrosion resistance, and two filters are installed in the middle of the pipe to prevent soot from entering the FT-IR.

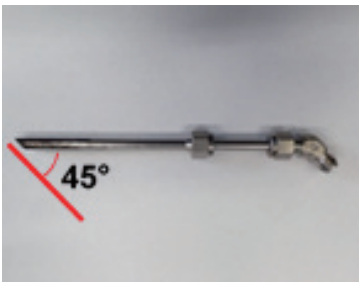

Fig. 3 Probe

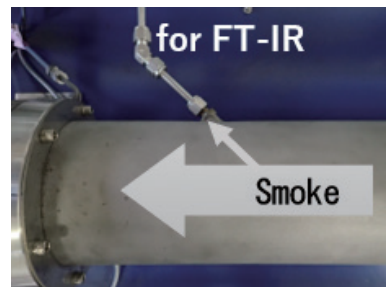

Fig. 4 Probe insertion

\subsection{Outline of the new combustion test device}

Based on the consideration in Sections 2.1 to 2.3, a new combustion test device, the CCM-IR was fabricated as shown in Fig. 5. The outline of the CCM-IR test device is shown in Fig. 6. The CCM part of the device evaluates the combustion behavior, HRR and smoke production, while the FT-IR part evaluates the components of the combustion gas.

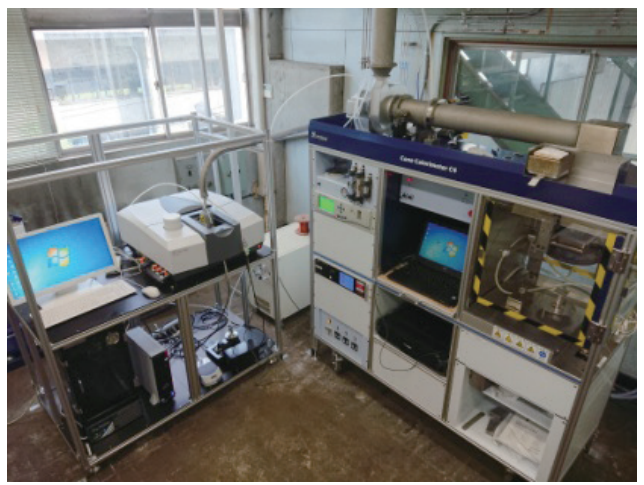

Fig. 5 Appearance of the CCM-IR test device

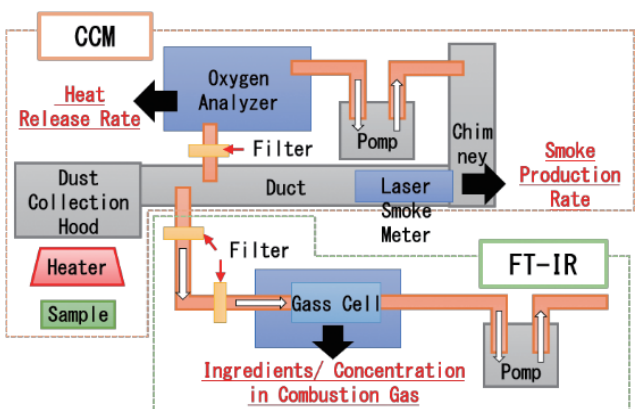

Fig. 6 Outline of the CCM-IR

\section{Test method by CCM-IR test device}

\subsection{Test method}

When the CCM test is started, the specimen begins to heat up. At the same time, an electric spark is triggered above the specimen to ignite the combustible gas produced through heating as shown in Fig. 7(a). The HRR generated by the combustion is measured with use of the oxygen analyzer as shown in Fig. 7(b), and the smoke production is measured by the laser smoke meter.

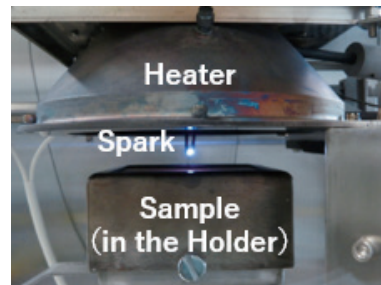

(a) Electric Spark

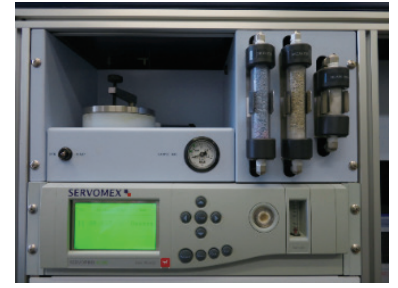

(b) Oxygen analyzer

\section{Fig. 7 External views of the CCM test device}

The FT-IR system is synchronized with the start signal of the CCM test system, so that the FT-IR system starts measuring the combustion gas at the same time. Table 3 shows the specifications of the CCM-IR test device.

\subsection{Test Results of the CCM-IR}

The following is an example of the results obtained when the CCM-IR test device combusted an aluminum foam resin laminates used as a wall material in rolling stock, for approximately 10 minutes. 
Table 3 Specifications of the CCM-IR

\begin{tabular}{|c|c|}
\hline Radiant heat flux & $\begin{array}{c}10 \mathrm{~kW} / \mathrm{m}^{2} \text { to } 100 \mathrm{~kW} / \mathrm{m}^{2} \\
\text { (practical maximum } 70 \mathrm{~kW} / \mathrm{m}^{2} \text { ) }\end{array}$ \\
\hline Size of specimen & $\begin{array}{c}\text { Length } 100 \mathrm{~mm} \text { x width } 100 \mathrm{~mm} \\
\text { Thickness } 50 \mathrm{~mm} \text { or less }\end{array}$ \\
\hline Measurement & 1 second interval \\
frequency & (CCM test system) \\
& $\begin{array}{c}1.08 \text { second interval } \\
\text { (FT-IR system) }\end{array}$ \\
Gas to be measured & $\mathrm{CO} \mathrm{CO}_{2}, \mathrm{HCl}, \mathrm{HCN}, \mathrm{NO}$, \\
& $\mathrm{NO}_{2}, \mathrm{SO}_{2}, \mathrm{HBr}, \mathrm{HF}$ \\
Total 9 types $($ compliant with \\
EN45545)
\end{tabular}

\subsubsection{Test Results from the CCM test device}

Test results from the CCM are shown in Fig. 8. These data can provide the ignition time, maximum HRR, THR, maximum smoke production rate, and total amount of smoke production, etc.

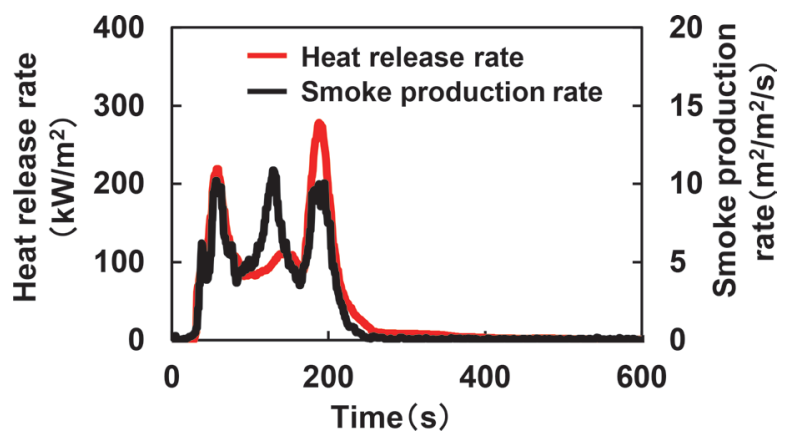

Fig. 8 Heat release rate (HRR) and smoke production rate

In this test, the HRR is determined by oxygen consumption method. This method is based on the result of the amount of oxygen consumed by combustion, the HRR indicates an almost constant value of $13.1 \mathrm{MJ}$ per $1 \mathrm{~kg}$ of oxygen, independent of the materials [2]. The amount of smoke production is calculated by the absorption degree of the laser beam when the combustion gas is irradiated with a laser beam.

\subsubsection{Test results from the FT-IR}

In the measurement of generated gas using the FT-IR, the infrared simply irradiates to the gas passing through the gas cell. Depend on the molecules structure in the generated gas, the specific infrared wavelength is absorbed by specific bond of gas molecule and obtained infrared absorption spectrum is different from respective gases. As an example, the infrared absorption spectrum after ignition is shown in Fig. 9. The species of gas are identified from the peak position of the spectrum, and the concentration of the gas is quantitatively evaluated from the peak height. By the accumulated measurement, the time-dependent change in the infrared absorption spectrum can be obtained as shown in Fig. 10.

Converting the spectrum to the concentration of respective gas, the time-dependent change of the generated gas is obtained as shown in Fig. 11.

In addition, combining with the CCM results described in pre-

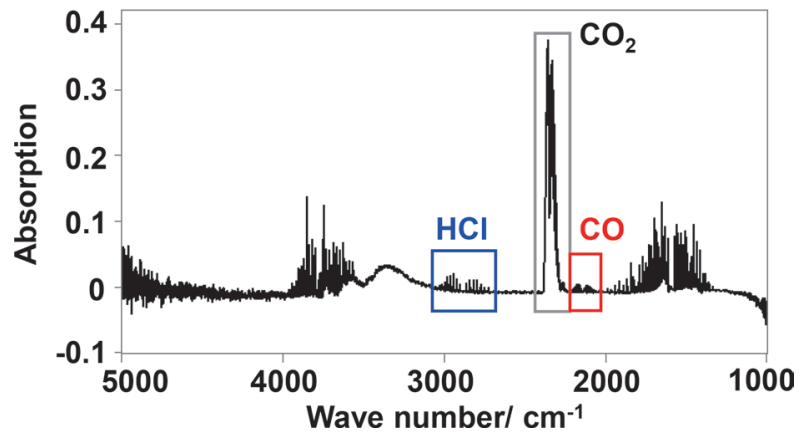

Fig. 9 Infrared absorption spectrum after ignition

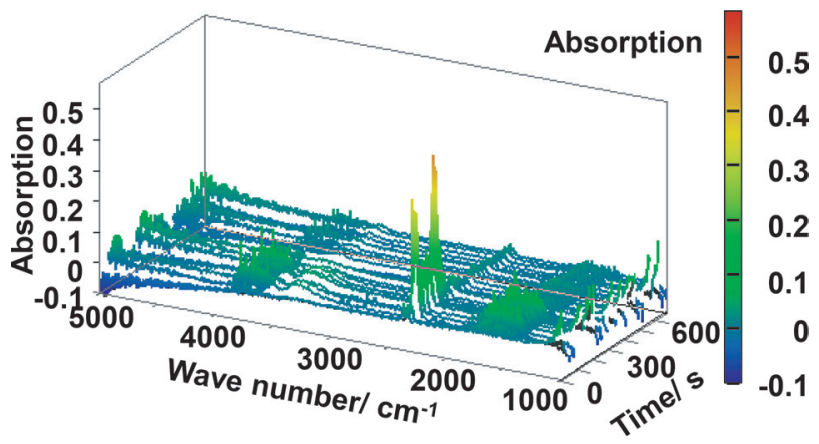

Fig. 10 Change in infrared absorption spectrum over time

vious section, means that a simultaneous evaluation between the amount of heat release rate and smoke production and the time-dependent change of the gas components during the combustion, can be performed.

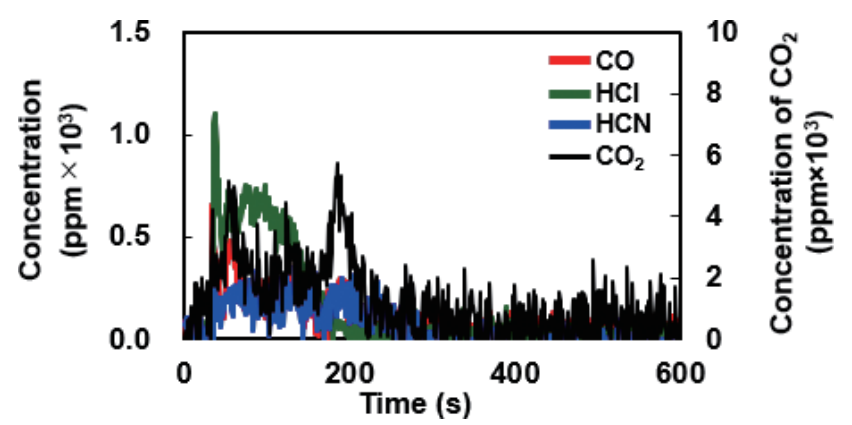

Fig. 11 Measurement results of combustion gas components

4. Measurement of combustion gases of materials for railway rolling stock

\subsection{Test products}

The test products are selected from the materials commonly used in current railway rolling stock, as shown in Table 4, which include three types of fire-retardant products: polyvinyl chloride floor coverings (PVC floor coverings), rubber floor coverings, and seat moquette; and two types of noncombustible products: decorative laminates and aluminum foam resin laminates. The product of the decorative laminates conform to the latest interpretation standard of ordinance No.151 [3] and has the performance to be used as a ceiling material for passenger's cabin for subways and Shinkansen vehicle. The aluminum foamed resin laminates are the same product 
as shown in Section 3.2.

Table 4 Test Products

\begin{tabular}{|c|c|c|c|}
\hline & Products & Materials & Appearance \\
\hline \multirow{3}{*}{$\begin{array}{c}\text { Fire- }^{-} \\
\text {Retard } \\
\text { ant }\end{array}$} & $\begin{array}{l}\text { PVC floor } \\
\text { covering }\end{array}$ & $\begin{array}{c}\text { PVC } \\
\text { Glass cloth }\end{array}$ & \\
\hline & $\begin{array}{c}\text { Rubber floor } \\
\text { covering }\end{array}$ & $\begin{array}{c}\text { Flame resistant } \\
\text { rubber }\end{array}$ & \\
\hline & $\begin{array}{c}\text { Seat } \\
\text { moquette }\end{array}$ & Polyester & \\
\hline \multirow{2}{*}{$\begin{array}{l}\text { Non- } \\
\text { Combu } \\
\text { stible }\end{array}$} & $\begin{array}{l}\text { Decorative } \\
\text { laminates }\end{array}$ & $\begin{array}{c}\text { Decorative film } \\
\text { Al panel }\end{array}$ & 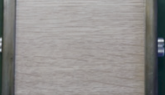 \\
\hline & $\begin{array}{l}\mathrm{Al} \text { foamed } \\
\text { resin } \\
\text { laminates }\end{array}$ & $\begin{array}{l}\text { Decorative film } \\
\text { Al panel } \\
\text { Foamed resin } \\
\text { Al panel }\end{array}$ & \\
\hline
\end{tabular}

\subsection{Test conditions}

The combustion gases of the materials for rolling stock were measured using the CCM-IR. The size of each test sample was approximately $100 \mathrm{~mm} \times 100 \mathrm{~mm}$, while the thickness was the normal thickness of the product. The radiant heat flux to the test product is $50 \mathrm{~kW} / \mathrm{m}^{2}$, which is the same value of the standard test of ordinance No.151 and the fire prevention performance tests of building materials [4]. The tests were conducted under the same conditions as in Section 3.1, with a test duration of 10 minutes.

\section{Results of tests on materials used on railway rolling stock by CCM-IR test device}

\subsection{Test results of flame-retardant materials}

\subsubsection{PVC floor coverings}

The results of combustion tests of PVC floor coverings are shown in Figs 12(a) and 12(b). When radiant heat flux was applied, the surface of the PVC floor coverings melted, releasing sudden large amounts of gas. Subsequently, all the material ignited and combusted approximately 20 seconds after the start of the test.

The amount of smoke produced exceeded that of the other products described below. The amount of smoke production depends on the amount of generated soot during combustion. Soot is likely to be generated when combustion remains incomplete due to insufficient oxygen. This suggested a high ratio of incomplete com- bustion for the PVC floor coverings.

The PVC floor coverings are mainly composed of poly vinyl chloride which is highly flame-retardant, and its oxygen index, which indicates the ratio of oxygen required for combustion, is higher than that of other resins [5].

Based on the gas measurement, hydrogen chloride was generated immediately after ignition, and the amount of hydrogen chloride was higher than in other products. This is because hydrogen chloride is generated through thermal decomposition of poly vinyl chloride. It is also found that carbon monoxide production also exceeded other materials. This is because of the large percentage of incomplete combustion as well as smoke production.

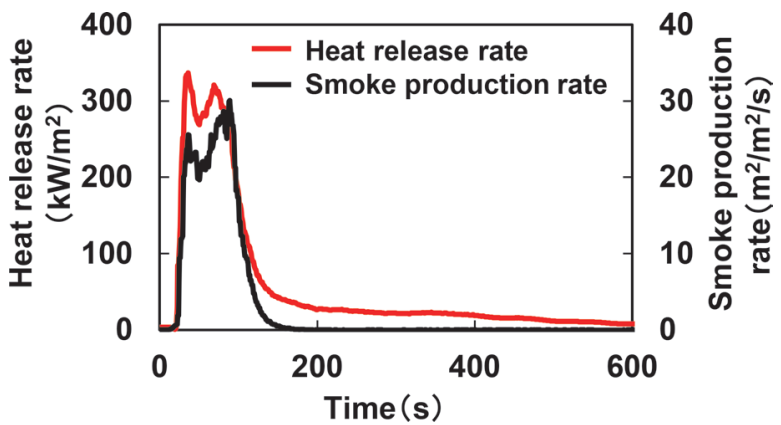

(a) Heat release rate (HRR) and smoke production rate

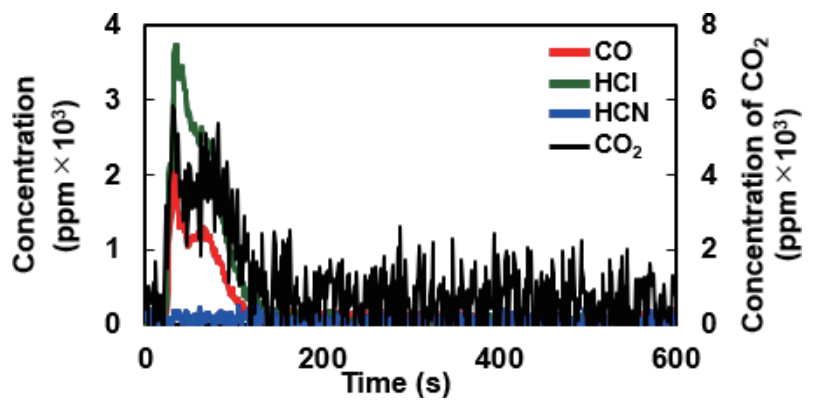

(b) Gas measurement results

Fig. 12 Combustion test results for PVC floor coverings

\subsubsection{Rubber floor coverings}

The results of combustion tests on rubber floor coverings are shown in Fig. 13(a) and (b). When radiant heat flux began, the surface of the rubber floor covering also melted and ignited. The ignition time of the rubber floor covering measured in this study as approximately 45 seconds, which is longer than that of the PVC floor covering, and the maximum HRR was smaller. These results can be explained by the fact that rubber does not contain oil, which is contained in poly vinyl chloride as a plasticizer; otherwise, the flame retardant contained in rubber. In addition, as shown in Fig. 13(a), since rubber floor coverings require a longer time to combust, the maximum smoke production rate was smaller than that of PVC floor coverings; therefore, the percentage of incomplete combustion was also smaller.

Based on the gas measurement, the main component of the generated gases during the combustion of rubber floor coverings were carbon dioxide and carbon monoxide. This is because rubber floor coverings, unlike PVC floor coverings, are mainly composed of chain hydrocarbon; therefore, they contain fewer other elements that generate gases other than carbon dioxide and carbon monoxide. 


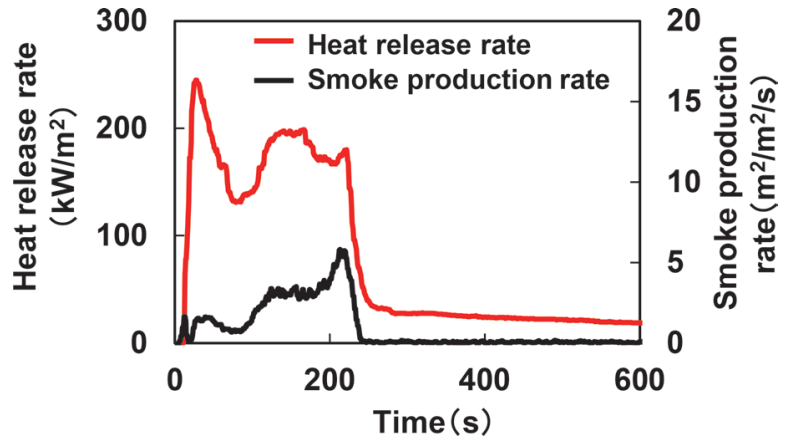

(a) Heat release rate (HRR) and smoke production rate

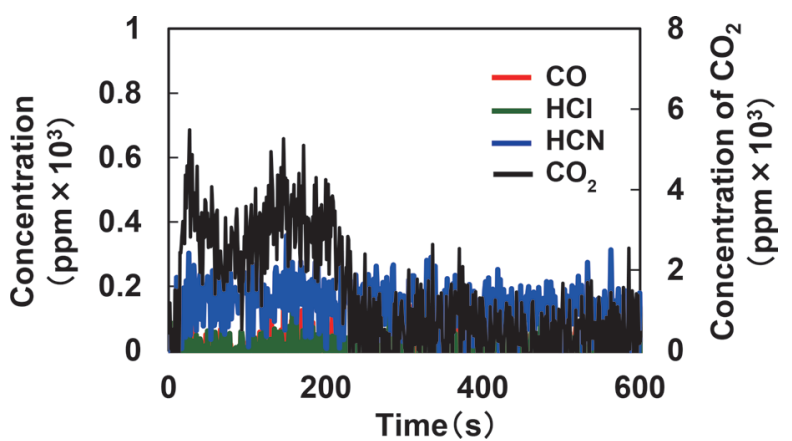

(b) Gas measurement results

Fig. 13 Results of combustion test of rubber floor covering

\subsubsection{Seat moquette}

The results of the combustion tests on the seat moquette are shown in Fig. 14 (a) and (b).

Since the seat moquette is very thin and light compared to the previous materials, all the material combusted immediately after the start of test and was automatically extinguished in short time. The maximum HRR was the highest among the materials measured in this study. On the other hand, the maximum smoke production rate was small compared to the HRR. This may be due to the fact that the seat moquette is very thin but the surface area in contact with air is significant, relative to the volume of the material. Therefore, incomplete combustion is less likely to occur.

Based on the gas measurement, it was confirmed that no toxic gases other than carbon dioxide and carbon monoxide were generated in the combustion of the seat moquette. Most of the seat moquette is composed of polyester fibers that do not contain halogen or nitrogen.

\subsection{Measurement results of nonflammable materials}

\subsubsection{Decorative laminates}

The results of combustion tests on decorative laminates are shown in Fig. 15(a) and 15(b).

The maximum HRR and the maximum smoke production rate of the decorative laminates are the smallest among the test products. The reason is that the only combustible component of the decorative laminates is the thin decorative film on the surface.

Based on the gas measurement, the main component of the generated gases during the combustion of the decorative laminates was carbon dioxide, and almost no other gas components were detected. This is because the only combustible component of the dec-

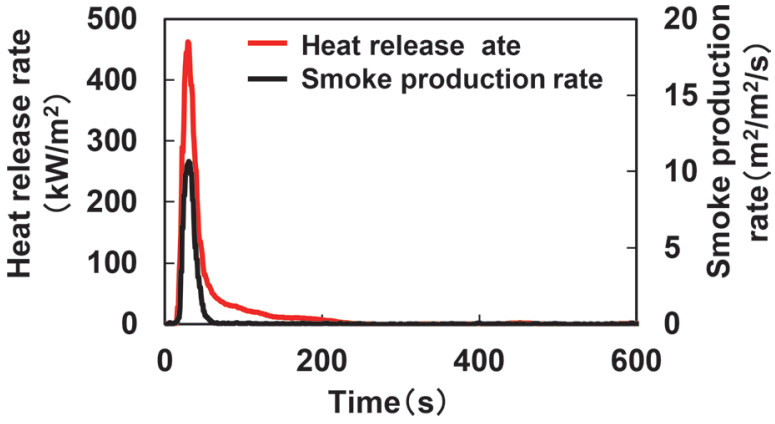

(a) Heat release rate (HRR) and smoke production rate

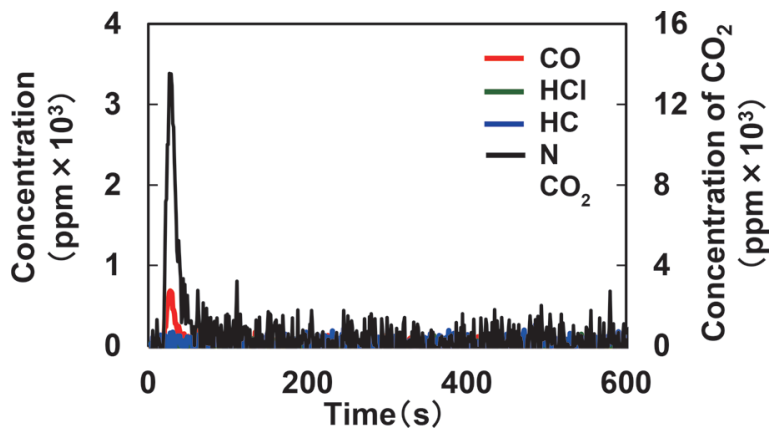

(b) Gas measurement results

\section{Fig. 14 Results of combustion test of seat moquette}

orative laminates was the thin decorative film on the surface, which does not contain specific elements, halogen, nitrogen, and so on. There was a sufficient amount of air to combust the products without incomplete combustion.

\subsubsection{Aluminum foamed resin laminates}

The combustion test results for aluminum foamed resin laminates are the same as those shown in Figs 8 and 11. Based on Fig. 8, there are four stages in the combustion of aluminum foamed resin laminates: the first stage of combustion, in which the decorative film on the surface ignites and combusts; the second stage of combustion, in which the decorative film combusts out and the molten internal foamed resin begins to combust; the third stage of combustion, in which the surface aluminum plate deforms greatly and the internal foamed resin begins to violently combust; and the final stage, in which the foamed resin finishes to combust and the flames gradually abate.

Comparing these results with Fig. 11, the peak of hydrogen chloride derived from the combustion of the decorative sheet was observed in the early stage of combustion. Carbon monoxide due to incomplete combustion was also generated.

In the latter stage of combustion, a large peak of carbon dioxide was observed due to the combustion of the foamed resin; meanwhile, the amount of carbon monoxide generated is decreased compared to the early stage of combustion. This is probably due to the suppression of incomplete combustion as a result of the gradual expansion of combustion. The successive generation of hydrogen cyanide was observed in all stages of combustion. The hydrogen cyanide was assumed to be generated through pyrolysis from the urethane foam inside.

As described above, by using the newly designed and fabricated CCM-IR test device, it was possible to understand various behaviors, including gas generated through combustion, in real time. 


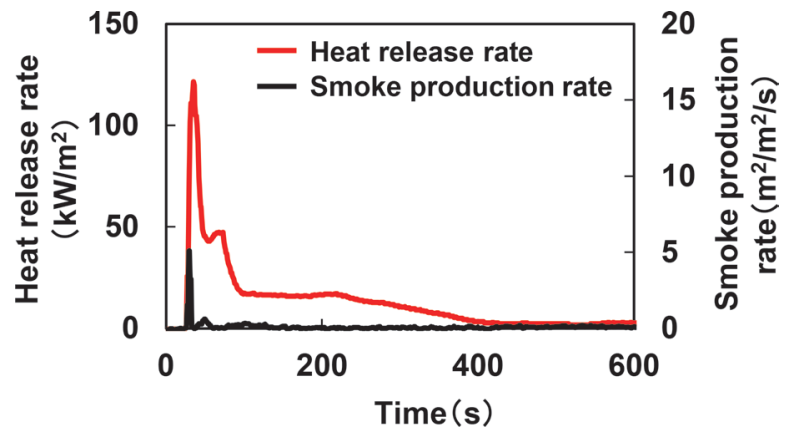

(a) Heat release rate (HRR) and smoke production rate

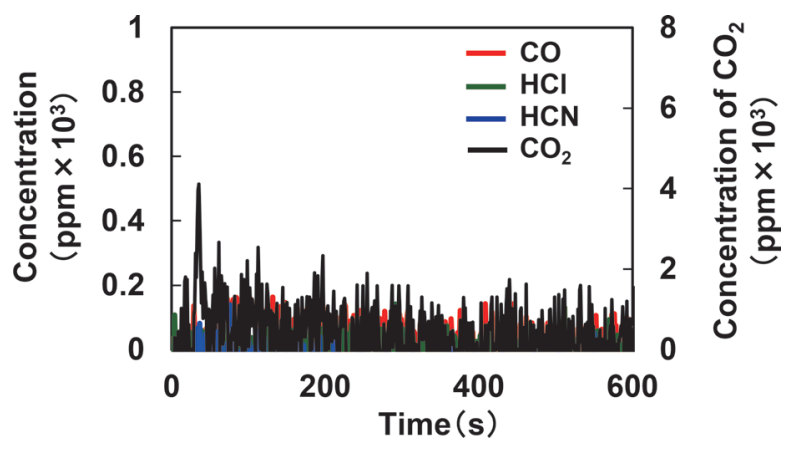

(b) Gas measurement results

Fig. 15 Results of combustion test of Laminated Panel

\section{Conclusion}

The authors designed and fabricated a new combustion test device that can simultaneously measure the time-dependent changes in combustion phenomena through the combustion of materials for railway rolling stock. The findings are described below.

(1) The authors designed and fabricated a cone calorimeter combustion test device combined with an FT-IR gas analyzer, which is suitable to evaluate materials used on railway rolling stock and enables simultaneous measurement of time-dependent changes in calorific value, smoke production and gas generation.

(2) Based on CCM-IR tests on typical products used on railway rolling stock, such as vinyl chloride floor coverings and aluminum foam resin laminates, toxic gases, hydrogen chloride and hydrogen cyanide, were observed from the early stage of combustion due to elements contained in the materials.

(3) Products with few combustible components, such as seat moquette and decorative laminates, were found to produce less smoke and carbon monoxide because incomplete combustion was less likely to occur.

(4) For laminated materials, such as aluminum foam laminates, the CCM-IR test is effective for evaluating the time-dependent changes not only in combustion behavior but also in gases generated during the combustion stage.

These results demonstrate that the new combustion test device is useful not only to grasp the combustion performance of materials but also to develop higher performance materials against fire. The data obtained from this test device may also contribute to fire simulations of rolling stock.

\section{References}

[1] EN45545-2 : Railway applications-Fire protection on railway vehicles, 2013.

[2] Huggett, C. : Fire and Materials, No. 4, pp. 61-65, 1980.

[3] Ministry of Land, Infrastructure, Transport and Tourism (Japan), Ordinance No. 151, "Technical Regulatory Standards on Japanese Railways," Chapter 8, Section 5, Article 83 (in Japanese).

[4] Building Guidance Division, Housing Bureau, Ministry of Construction (Japan), "Explanation of the revised Building Standards Act (enforced in the second year) on June 1, 2000," 2000 (in Japanese).

[5] M.M.Hirschler.:Makromol.Chem.Macromol.Symp., Vol. 29, pp. 133-153, 1989.

\section{Authors}

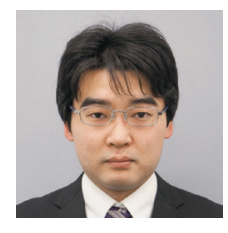

Sho YAMANAKA

Assistant Senior Researcher, VibrationIsolating Materials Laboratory, Materials Technology Division

Research Areas: Railway Fire, Polymer Sciences

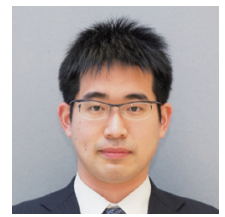

\section{Tadashi TOYOHARA}

Researcher, Vibration-Isolating Materials Laboratory, Materials Technology Division Research Areas: Railway Fire, Polymer Sciences

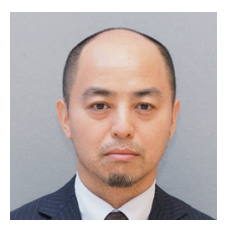

Mikiya ITO, Ph. D.

Senior Chief Researcher, Head of VibrationIsolating Materials Laboratory, Materials Technology Division Research Areas: Railway Fire, Polymer Sciences 